\title{
GROUND TRAVEL-INDUCED IMPAIRMENT OF WELLNESS IS ASSOCIATED WITH FITNESS AND TRAVEL DISTANCE IN YOUNG SOCCER PLAYERS
}

\author{
Alireza Rabbani ${ }^{1}$ and Martin Buchheit ${ }^{2}$ \\ ${ }^{1}$ Department of Exercise Physiology, Faculty of Physical Education and Sport Sciences, \\ University of Isfahan, Isfahan, Iran \\ ${ }_{2}^{2}$ Performance Department, Paris Saint Germain F.C, Saint-Germain-en-Laye, France
}

Original scientific paper

UDC: $159.944: 796.332-053.6$

\begin{abstract}
:
The aims of this study were to 1) investigate the influence of ground travel on wellness measures, and 2) examine the possible influence of travel distance and fitness on the magnitude of these possible changes. Compared with home matches, wellness measures showed moderate-to-large impairments of wellness of soccer players for away matches the day prior to the match (D-1) (range; +5 to $68 \%$, [90\%CL 1-88]; standardized difference: range; +.6 to +1.75 [.1-2.07]) and small-to-large impairments on the day of the match (D-0, range; +7 to +68.1 [-1.6-87.5]; standardized difference, range; +.24 to 1.78 , [-.06-2.15]), respectively. There were large and very large negative relationships between the increases of fatigue $(\mathrm{r}=-.84,90 \% \mathrm{CL}$ $-.95 ;-.56)$ or soreness $(\mathrm{r}=-.80,-.93 ;-.84)$ at $\mathrm{D}-1$ and players' fitness. There were also very large positive correlations between actual wellness measures and traveling distance to away locations ( $\mathrm{r}$ range: .70 to .87). Ground travel-induced impairment of wellness is associated with fitness and distance of away locations in young soccer players. Simple wellness questionnaires could be used to effectively monitor young soccer players' freshness and readiness to train or compete during away games.
\end{abstract}

Key words: Association football, fatigue, psychometric measures, monitoring, home advantage

\section{Introduction}

Soccer teams in all leagues all over the world have to travel regularly for away matches during a competitive season, with the travel distance often related to playing standard (the higher the playing standard, the greater the travel distance). There is a tendency for teams to perform better at home than away, which is generally referred to as home advantage (Goumas, 2013; Pollard, 2008). Although myriad of variables have been proposed as underlying causes of this phenomenon, potential impairments in players' wellness known as travel fatigue or travel weariness are of particular interest for physiologists and sports scientist when monitoring players' readiness to compete and/or train (Waterhouse, Reilly, \& Edwards, 2004).

According to the results of very recent studies investigating the effect of air travel on wellness (Fowler, Duffield, \& Vaile, 2014, 2015; Fowler, Duffield, Waterson, \& Vaile, 2015), there seems to be a negative effect of this type of travel on wellness in team sport players. In particular, Fowler et al., (2014) not only highlighted the negative effect of travel on overall wellness, but also the subsequent performance decrement in soccer players, demonstrating an important effect of wellness on performance. However, to date these investigations were conducted in adult players, and the effects of travel on wellness responses in young academy soccer players are yet to be determined.

While in a professional environment, adult teams usually fly to away locations (Fowler, et al., 2014, 2015a, 2015b; McGuckin, Sinclair, Sealey, \& Bowman, 2014), young academy players generally have to travel by bus or train due to their restricted budget. Various factors determine traveling distance, such as playing standard and country size. For teams playing in the highest youth leagues in wide countries, the traveling distance can vary from several kilometers (same city, $<30 \mathrm{~min}$ ) up to 1,300 $\mathrm{km}$ (travel across the country, $>14-16 \mathrm{hrs}$ ). Although it seems that the amount of travel-induced impairment of wellness in young soccer players might be greater than for adults (i.e. using systematically 
ground vs. air travel, which leads to longer travel durations), no data exist on the effects of ground travel on their wellness and/or performance. Since it has been reported that traveling for many hours (i.e. international air travel) impairs wellness more than shorter trips (i.e. domestic air travel), an association between wellness impairment and distance/ hours of traveling might be expectable (Fowler, et al., 2015a). However, whether the distance of ground travel also plays a role and has a relationship with wellness change/impairment is also unknown. An important factor that may affect the time course of recovery in soccer is fitness (Johnston, Gabbett, Jenkins, \& Hulin, 2015; Nédélec, et al., 2012). Subsequently, it could be hypothesized that fitter players may experience less fatigue or soreness than their less fit teammates when recovering from training/matches, but also when traveling extensively for away matches. At present, however, the relationship between players' wellness and fitness levels as well as travel distance for away matches is still unclear.

When it comes to monitoring players' fatigue/ freshness to train/compete, both objective and subjective indices are generally collecting by practitioners working with various teams (Buchheit, 2014; Saw, Main, \& Gastin, 2016). Objective measures (e.g. heart rate data, saliva measures, jump performance) usually need sophisticated devices that are not commonly available in many clubs, particularly for young academy players. In contrast, subjective measures such as perceived physical and psychological well-being are relatively simple to attain, they are cheap and non-invasive (Saw, et al., 2016). Importantly, subjective measures may have superior sensitivity and greater consistency than objective measures, and could reflect both acute and chronic training loads (Saw, et al., 2016). For the aforementioned reasons, perceived wellness measures are today considered as one of the most promising tools to monitor (young) soccer players. Therefore, the aims of the present study were to 1) investigate the influence of ground travel on perceived wellness measures, and 2) examine the possible influence of travel distance and fitness on the magnitude of these possible changes.

\section{Methods}

\section{Participants}

Data from seventeen young soccer players (mean $\pm \mathrm{SD}, 17.8 \pm .4$ years of ages, $68.5 \pm 5 \mathrm{~kg}, 178.1 \pm$ $5.1 \mathrm{~cm}$ and $12.5 \pm 1 \%$ of body fat) from a U19 Iran premier league team were used. Their high-intensity intermittent running performance, assessed using the Yo-Yo Intermittent Recovery Test Level 1 (Yo-YoIR1 (Bangsbo, Iaia, \& Krustrup, 2008) one week after eight weeks of preparation period, was
$1,920 \pm 264 \mathrm{~m}$. The players trained six times per week plus a weekend match. The first day after the match $(D+1)$ a recovery session was organized including jogging and stretching. On the second day following the match $(\mathrm{D}+2)$ the players performed resistance training. The third day following the match $(\mathrm{D}+3)$ included a high-intensity interval training as well as tactical training. On the fourth day $(\mathrm{D}+4)$ a training session was conducted including speed, agility, quickness training and tactical training. The fifth $(\mathrm{D}+5)$ and sixth $(\mathrm{D}+6$, i.e. $\mathrm{D}-1)$ training days included technical and tactical training in which training load was gradually decreased to prepare the players for the upcoming match day. All trips were organized for the team to reach the away location in the morning (i.e. before 12 a.m.) of the day before the match (D-1). In practice, for trips that lasted less than six hours, the team departed early in the morning (D-1). For trips of longer durations/ distances ( $>6$ hours), the team left for a match destination the preceding night (range of time: 8-12 p.m.). All training sessions on D-1 were scheduled according to the match kick-off time (i.e. 2 to 3 p.m.). These data were the result of monitoring the players, where players' activities are routinely measured over the course of a competitive season. Therefore, the ethics committee clearance was not required (Winter \& Maughan, 2009). The study conformed, nevertheless, to the recommendations of the Declaration of Helsinki.

\section{Data collection}

During an entire in-season period, which included 10 home and 10 away matches (11 teams in the league), wellness variables data were collected for each player about one hour before each training or match. The wellness data were consistently collected immediately before soccer practices on D-1, i.e. 2 to 4 hours after arrival. Departure to return home was consistently within 1 to 2 hours after a match. Data collection at D+1 was consistently in the afternoon (range of time; 2 to 4 p.m.).

\section{Monitoring wellness (Hooper Scales)}

The Hooper Scales Questionnaire was used to assess players' wellness (Hooper \& Mackinnon, 1995). The questionnaire comprised four questions related to perceived sleep quality, stress, muscle fatigue and soreness, with each question to be scored on a 7-point scale (with 1 and 7 representing very good and poor wellness ratings, respectively). The overall wellness known (Hooper Scales) was determined by summing the four scores.

\section{Statistical analyses}

The data were presented as means (SD). Changes in the Hooper Scales and its separate wellness 
variables (i.e. sleep, stress, fatigue, and soreness) for home and away matches (D-1, D-0 and D+1) were analyzed using standardized differences or effect size (ES) (Cohen, 1988). The Hopkins Scale (www.sportsci.org/resource/stats) was used for their interpretation: $<0.2$ : trivial; $0.2-0.6$ : small; $0.6-1.2$ : moderate; $>1.2$ : large (Batterham \& Hopkins, 2006). A magnitude-based inference approach was used to analyze the chance that true changes were clear or trivial. Probabilities were also calculated to determine whether the true differences were lower than, similar to, or higher than the smallest worthwhile difference or change (SWC, $.2 \times$ between-subject SD) (Hopkins, Marshall, Batterham, \& Hanin, 2009). Pearson correlation coefficients were also used to 1) measure the relationship between travel-induced responses in wellness measure with Yo-YoIR1 performance, and 2) determine the relationship between the travel distance for each away match with players' wellness for each day (D-1, D-0 and $\mathrm{D}+1)$. The magnitude of the correlations ( $\mathrm{r}, 90 \%$ confidence limits, CL) was assessed according to the scale of Hopkins (Hopkins, et al., 2009).

\section{Results}

The data for one match could not be collected, so the final dataset included data for 19 matches (10 home and 9 away ones). The complete data set for all matches including Yo-YoIR1 and wellness measures was $11 \times 19$.

\section{Differences in wellness between home and away matches}

Differences in wellness measures between home and away matches on the three investigated days (D-1, D- $0, D+1)$ are shown in Tables 1, 2 and 3 , respectively. On D-1, there were certain and large impairments in all wellness measures for the away compared with home matches, except for stress which showed only a likely moderate impairment (Table 1). On D-0, there were possibly-to-very likely small impairment in sleep, stress and fatigue, while soreness showed almost certainly large decreases in away matches (Table 2). On $\mathrm{D}+1$, differences in wellness measures were trivial-to-small with probabilities ranging from unclear-to-possible.

Table 1. Wellness measures on the day prior to the match (D-1) for home and away locations

\begin{tabular}{|c|c|c|c|c|c|}
\hline \multirow{2}{*}{$\begin{array}{l}\text { Variable } \\
\text { Hooper Scales }\end{array}$} & \multicolumn{2}{|c|}{$\begin{array}{c}\text { Day prior to match (D-1) } \\
\text { Home Away }\end{array}$} & \multirow{2}{*}{$\begin{array}{c}\text { \% difference } \\
(90 \% \mathrm{Cl}) \\
56.5 \\
(44.2 ; 69.8)\end{array}$} & \multirow{2}{*}{$\begin{array}{c}\begin{array}{c}\text { Standardized } \\
\text { difference }(90 \% \mathrm{CI}) \\
\text { Rating }\end{array} \\
\begin{array}{c}1.75(1.43 ; 2.07) \\
\text { Large }\end{array}\end{array}$} & \multirow{2}{*}{$\begin{array}{c}\% \text { greater/similar/lower } \\
\text { values for away vs. } \\
\text { home matches }\end{array}$} \\
\hline & $6.9(1.50)$ & $10.55(1.31)$ & & & \\
\hline Sleep & $2.12(.61)$ & $3.50(.74)$ & $\begin{array}{c}67.9 \\
(44.8 ; 88.1)\end{array}$ & $\begin{array}{c}1.7(1.33 ; 2.07) \\
\text { Large }\end{array}$ & $\begin{array}{c}100 / 0 / 0 \\
\text { Almost certain }\end{array}$ \\
\hline Stress & $1(0)$ & 1.06 (.12) & $\begin{array}{c}5.9 \\
(.9 ; 11.0)\end{array}$ & $\begin{array}{l}.68(.11 ; 1.25) \\
\text { Moderate }\end{array}$ & $\begin{array}{l}92 / 7 / 1 \\
\text { Likely }\end{array}$ \\
\hline Fatigue & $2.13(.64)$ & $2.96(.30)$ & $\begin{array}{c}44.1 \\
(30.4 ; 59.2)\end{array}$ & $\begin{array}{c}1.23(.9 ; 1.57) \\
\text { Large }\end{array}$ & $\begin{array}{c}100 / 0 / 0 \\
\text { Almost certain }\end{array}$ \\
\hline Soreness & $2.16(.49)$ & $2.96(.30)$ & $\begin{array}{c}40.5 \\
(28.1 ; 54.1)\end{array}$ & $\begin{array}{l}1.3(.95 ; 1.65) \\
\text { Large }\end{array}$ & $\begin{array}{c}\text { 100/0/0 } \\
\text { Almost certain }\end{array}$ \\
\hline
\end{tabular}

Note. Greater wellness values stand for impaired wellness. Values are mean \pm SD. Cl: confidence interval. \%: percentage.

Table 2. Wellness measures on the match day (D-0) for home and away locations

\begin{tabular}{|c|c|c|c|c|c|}
\hline \multirow{2}{*}{$\begin{array}{l}\text { Variable } \\
\text { Hooper Scales }\end{array}$} & \multicolumn{2}{|c|}{$\begin{array}{l}\text { Match day (D-0) } \\
\text { Home Away }\end{array}$} & \multirow{2}{*}{$\begin{array}{c}\begin{array}{c}\% \text { difference } \\
(90 \% \mathrm{Cl})\end{array} \\
7.2 \\
(.7 ; 14)\end{array}$} & \multirow{2}{*}{$\begin{array}{c}\text { Standardized } \\
\text { difference }(90 \% \mathrm{Cl}) \\
\text { Rating } \\
.31(.03 ; .59) \\
\text { Small }\end{array}$} & \multirow{2}{*}{$\begin{array}{c}\% \text { greater/similar/lower } \\
\text { values for away vs. } \\
\text { home matches }\end{array}$} \\
\hline & $6.4(1.27)$ & $6.81(1.30)$ & & & \\
\hline Sleep & $1.70(.44)$ & $1.81(.44)$ & $\begin{array}{c}7 \\
(-1.6 ; 16.4)\end{array}$ & $\begin{array}{c}.24(-.06 ; .54) \\
\text { Small }\end{array}$ & $\begin{array}{l}\text { 59/40/1 } \\
\text { Possibly }\end{array}$ \\
\hline Stress & $1.33(.4)$ & $1.16(.14)$ & $\begin{array}{c}-9.8 \\
(-16.8 ;-2.2)\end{array}$ & $\begin{array}{c}-.36(-.64 ;-.08) \\
\text { Small }\end{array}$ & $\begin{array}{l}\text { 0/16/83 } \\
\text { Likely }\end{array}$ \\
\hline Fatigue & $1.68(.48)$ & $1.94(.48)$ & $\begin{array}{c}17.2 \\
(8.1 ; 27.1)\end{array}$ & $\begin{array}{c}.47(.23 ; .72) \\
\text { Small }\end{array}$ & $\begin{array}{c}97 / 3 / 0 \\
\text { Very likely }\end{array}$ \\
\hline Soreness & $1.81(.46)$ & $2.95(.24)$ & $\begin{array}{c}68.1 \\
(50.7 ; 87.5)\end{array}$ & $\begin{array}{c}1.78(1.41 ; 2.15) \\
\text { Large }\end{array}$ & $\begin{array}{c}100 / 0 / 0 \\
\text { Almost certain }\end{array}$ \\
\hline
\end{tabular}

Note. Greater wellness values stand for impaired wellness. Values are mean \pm SD. Cl: confidence interval. \%: percentage. 
Table 3. Wellness measures on the day after the match $(D+1)$ for home and away locations

\begin{tabular}{|c|c|c|c|c|c|}
\hline \multirow{2}{*}{$\begin{array}{l}\text { Variable } \\
\text { Hooper Scales }\end{array}$} & \multicolumn{2}{|c|}{$\begin{array}{l}\text { Day after the match }(D+1) \\
\text { Home Away }\end{array}$} & \multirow{2}{*}{$\begin{array}{c}\text { \% difference } \\
(90 \% \mathrm{Cl}) \\
-5.7 \\
(-14.7 ; 4.1)\end{array}$} & \multirow{2}{*}{$\begin{array}{c}\begin{array}{c}\text { Standardized } \\
\text { difference }(90 \% \mathrm{Cl}) \\
\text { Rating }\end{array} \\
-.37(-.98 ; .25) \\
\text { Small }\end{array}$} & \multirow{2}{*}{$\begin{array}{c}\% \text { greater/similar/lower } \\
\text { values for away vs. } \\
\text { home matches }\end{array}$} \\
\hline & $10.27(1.52)$ & $10.19(2.55)$ & & & \\
\hline Sleep & $2.55(.59)$ & $3.09(.86)$ & $\begin{array}{c}17.20 \\
(.9 ; 36.3)\end{array}$ & $\begin{array}{c}.56(.03 ; 1.1) \\
\text { Small }\end{array}$ & $\begin{array}{c}87 / 11 / 1 \\
\text { Likely }\end{array}$ \\
\hline Stress & 1.06 (.14) & $1.07(.17)$ & $\begin{array}{c}-0.6 \\
(-8.7 ; 8.3)\end{array}$ & $\begin{array}{c}-.05(-.72 ; .62) \\
\text { Trivial }\end{array}$ & $\begin{array}{l}26 / 39 / 35 \\
\text { Unclear }\end{array}$ \\
\hline Fatigue & $3.53(.64)$ & $3.06(.9)$ & $\begin{array}{c}-15.7 \\
(-26.8 ;-2.9)\end{array}$ & $\begin{array}{c}-.05(-.72 ; .62) \\
\text { Trivial }\end{array}$ & $\begin{array}{l}\text { 1/6/93 } \\
\text { Likely }\end{array}$ \\
\hline Soreness & $3.14(.71)$ & $3.14(.89)$ & $\begin{array}{c}-4.9 \\
(-13 ; 3.9)\end{array}$ & $\begin{array}{c}-.2(-.72 ; .62) \\
\text { Small }\end{array}$ & $\begin{array}{l}\text { 3/47/50 } \\
\text { Possibly }\end{array}$ \\
\hline
\end{tabular}

Note. Greater wellness values stand for impaired wellness. Values are mean \pm SD. Cl: confidence interval. \%: percentage.

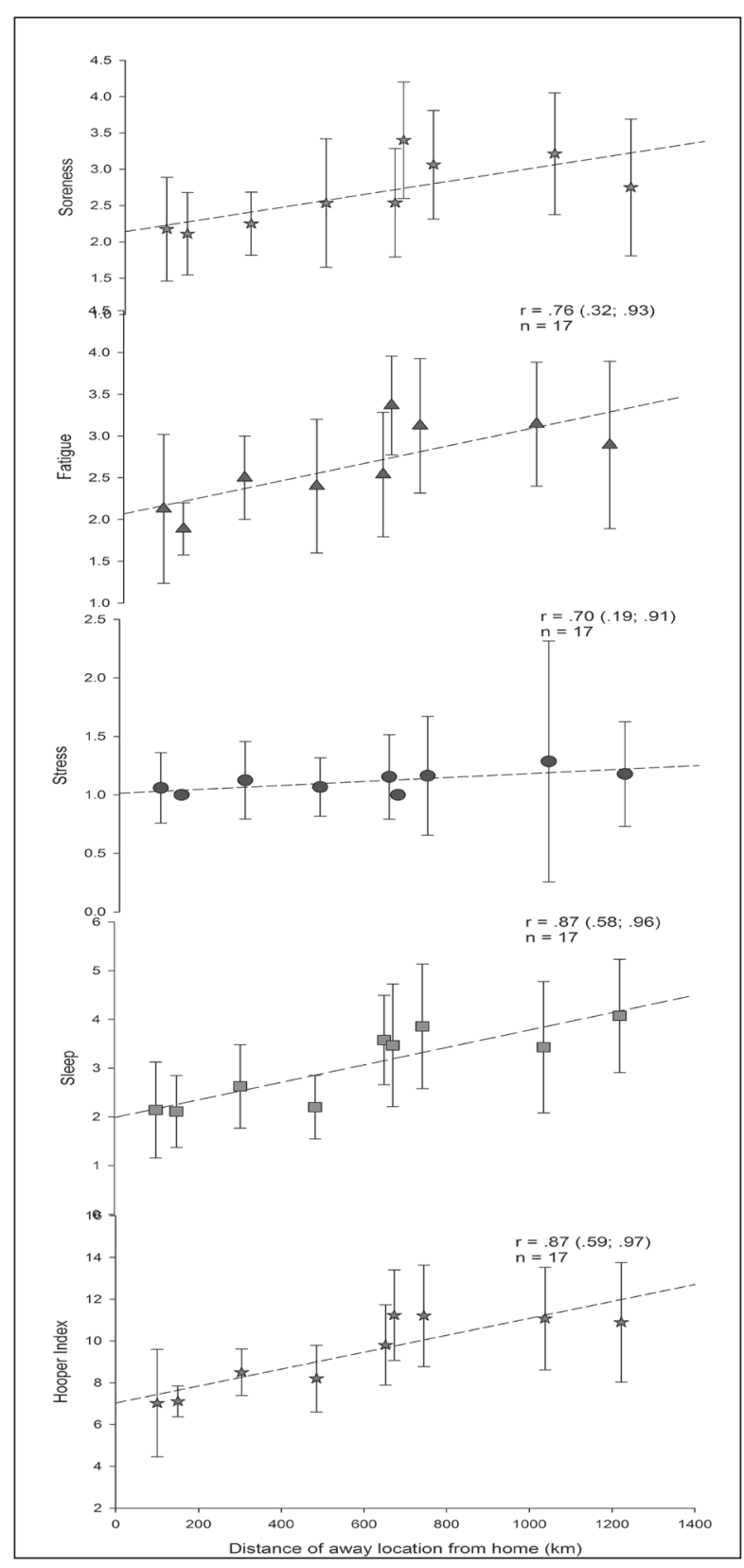

Figure 1. Relationship between team-average wellness responses (with 90\% confidence intervals) and the distance of away locations on the day prior to the match (D-1).

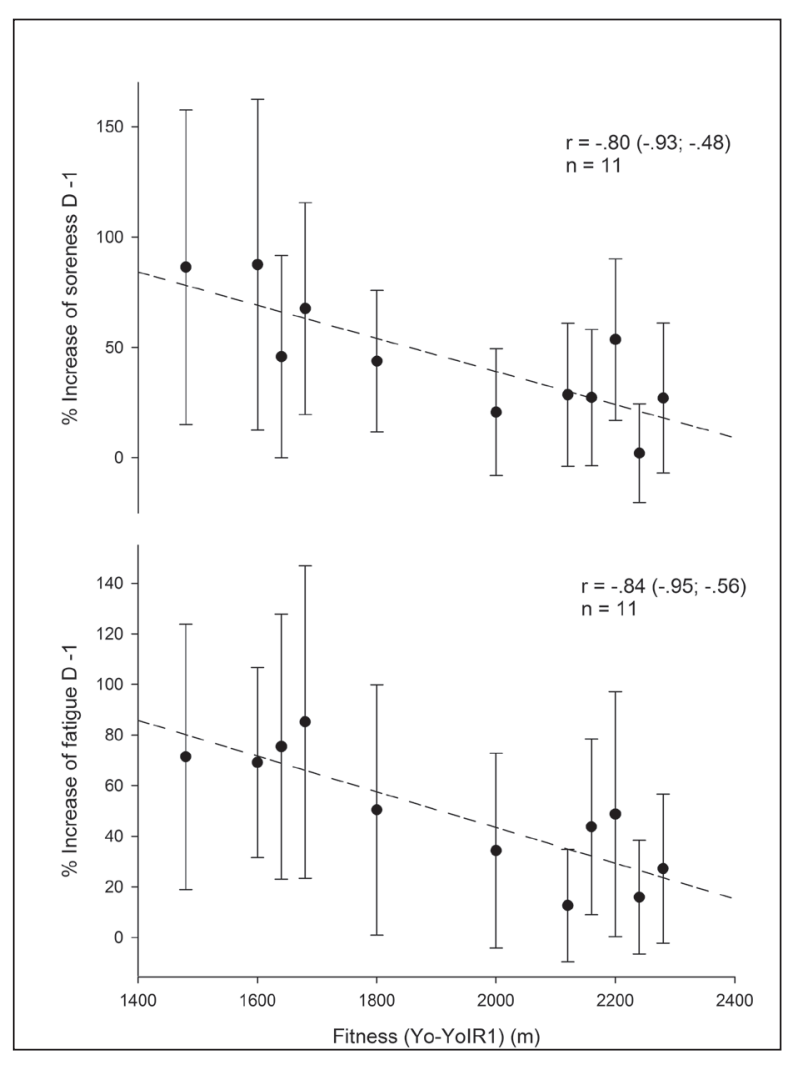

Figure 2. Relationship between player-average travel-induced changes in fatigue and soreness and fitness on the day prior to the match (D-1). Yo-YoIRI: Yo-Yo Intermittent Recovery Test Level 1.

\section{Relationship between wellness responses and distance traveled to away matches}

All actual wellness measures showed positive and large relationships with the distance traveled to the away locations, ranging from .70-.87 (Figure 1).

\section{Relationship between travel-induced wellness responses and fitness}

The negative correlations between travelinduced responses on D-1 and Yo-YoIR1 performance were very large for fatigue and soreness 
(Figure 2). All other correlation analyses for D-0 and $\mathrm{D}+1$ were trivial or unclear.

\section{Discussion and conclusions}

Monitoring players' wellness is receiving increased popularity in today's football to adjust training loads, prevent excessive fatigue and injuries (Saw, et al., 2016) and understand wellness responses to extensive trips to away matches (Fowler, et al., 2015a). The aims of this study were to 1) investigate the influence of ground travel on wellness measures, and 2) examine the possible influence of travel distance and fitness on the magnitude of these possible changes.

\section{Differences in wellness between home and away matches}

We observed for the first time that simple selfreported wellness measures such as the Hooper Scales were sensitive to ground travel in young academy players. More precisely, most of the wellness measures were almost certainly and largely impaired on D-1 (Table 1), confirming a negative effect of long trips on players' freshness after arrival (Fowler, et al., 2015a). Our data showed, however, that these wellness impairments had almost been recovered on D-0 (Table 2). This suggests that traveling to away locations a day before a match would likely help players to recover from their trip, and that securing one night at the away location may be of paramount importance for teams playing far away from home, particularly when young academy players travel by bus or train.

Interestingly, however, while sleep, stress and fatigue bounced back within their normal levels on D-0, soreness was still almost certainly and largely increased. Such an increase was even larger when compared with D-1 (i.e., ES of 1.78 vs. 1.3 on D-0 and D-1, respectively), which might be related to a delayed onset of muscle soreness (DOMS) following trips (Cheung, Hume, \& Maxwell, 2003). This suggests that the recovery from travel-induced DOMS may last longer than from general fatigue. Some special recovery strategies targeting neuromuscular recovery (e.g. cold water immersion, massage, not implemented in the present study though) may therefore be of special interest to attenuate player's muscle soreness after such types of trips (Nédélec, et al., 2012).

On D-1, stress showed a moderate increase when away locations be taken into account, probably due to players' higher anxiety during the journey (Waterhouse, et al., 2004). Sleep also showed a large detrimental response on D-1 for away locations, suggesting that ground traveling may be detrimental for players' sleep pattern/quality. The impairment of sleep quality is very likely related to the changes in sleep environment during longer trips and to anxiety of an early wake-up when departing in the morning for shorter distances (Waterhouse, et al., 2004). Wellness responses on $D+1$ were more equivocal (trivial to small effects) and might be more due to individual responses to match load and match outcomes than to travel per se.

Increased fatigue and soreness observed are in contrast, however, with some previous investigations on short air travels (Fowler et al., 2014; Fowler, et al., 2015b; McGuckin, et al., 2014). This suggests that long ground trips induce a substantially greater physical stress than short air travels. Interestingly, Fowler et al. (2015a) reported wellness impairment prior to a match when simulating air travel for 24 hours, but not after a 5-hour domestic flight in physically active males (estimated maximal oxygen uptake: $52.8 \mathrm{ml} / \mathrm{min}$ ). Taken together, these data suggest that the trip duration rather than traveling conditions per se (i.e. bus vs. airplane) may determine players' wellness responses.

\section{Relationship between mean wellness measures and distance traveled to away matches}

Another interesting and novel result in the present study was a very large and positive association between all subjective wellness scores and travel distance (Figure 1). This result confirms that distance and/or time spent on the road when traveling may be a decisive factor in determining wellness responses to travel, and it must be carefully considered by team managers when planning their trips. Considering a potentially detrimental effect of poor wellness on physical performance (Fowler, et al., 2015a), all possible actions to shorten the duration of trips, and/or make them more comfortable should be investigated (e.g. standard of bus or train, regular stops to stretch and exercise). The present data also suggest that simple, non-invasive and subjective monitoring tools, such as the Hooper Scales, are well sensitive to distance or duration of ground trips. The sensitivity of selfreported measures in our study supports the results of a very recent review (Saw, et al., 2016) demonstrating the usefulness of subjective measures to monitor athletes' training status.

All wellness subscales (i.e. sleep, stress, fatigue, and soreness; Figure 1) worsened linearly with increases in traveling distances, although a tendency to plateau was observed after $600-700 \mathrm{~km}$. While this suggests that there might be a ceiling effect of travel on wellness impairment, that is, plateaus after $600-700 \mathrm{~km}$ (or 7-8 hours), more invasive measures (e.g. electroencephalogram) might be needed to draw definitive conclusions. Differences in departure times, and in turn, in sleep time in the bus may also have impacted this relationship. For instance, for the longest trips $(>1,000 \mathrm{~km})$, departure time must be early enough on D-2 for players 
to have a full night sleep in the bus, which may actually be longer than for shorter overnight trips departing later (e.g. $700 \mathrm{~km})$.

\section{Relationship between travel-induced impairment of wellness and fitness}

Another interesting result of this study was a substantial association between mean travelinduced impairments in wellness measures on D-1 and Yo-YoIR1 performance (i.e. very large and large relationships for fatigue and soreness, respectively; Figure 2). Beneficial effect of fitness on physical recovery is actually in line with faster post game recovery reported in fitter vs. less fit rugby players (Johnston, et al, 2015). While correlations do not imply causality, these results suggest that the fitter the players, the lower the wellness impairment when traveling by bus or by train. The improvement of players' physical fitness may therefore not only enhance their physical and technical performance in matches (Carling, 2013), but could also attenuate the fatigue and soreness-induced increases when traveling.

In conclusion, we have shown for the first time in young academy players that, compared with home matches, wellness measures are impaired a day before and on day of away matches, and that the greater the travel distance, the greater the wellness impairment. We have also demonstrated that fitter players may experience less ground travelinduced wellness impairment when traveling than their less fit counterparts. The present results confirm the need for arrival to the match destination a day prior to an away match when traveling for many hours and to apply some recovery strategies like cold water immersions (Nédélec, et al., 2012) after arrival to attenuate increased soreness that may last until the game day. Our results also suggest that, despite a somewhat questionable impact of fitness on match outcomes (Carling, 2013; Mendez-Villanueva \& Buchheit, 2011), physical conditioning may still be regarded as an important component of training preparation in academy players subjected to long trips. Subsequently, the players' fitness level may also need to be taken into account when selecting players in team roosters, especially when playing away matches requiring extended travels. Finally, our study confirms the value of self-reported wellness questionnaires, such as the Hooper Scales, which are cheap, non-invasive, non-fatiguing, sensitive and effective for monitoring players' readiness/fatigue to train/compete.

\section{References}

Bangsbo, J., Iaia, F.M., \& Krustrup, P. (2008). The Yo-Yo intermittent recovery test: A useful tool for evaluation of physical performance in intermittent sports. Sports Medicine, 38(1), 37-51.

Batterham, A.M., \& Hopkins, W.G. (2006). Making meaningful inferences about magnitudes. International Journal of Sports Physiology and Performance, 1(1), 50-57.

Buchheit, M. (2014). Monitoring training status with HR measures: Do all roads lead to Rome?. Frontiers in Physiology, 27(5), 73.

Carling, C. (2013). Interpreting physical performance in professional soccer match-play: Should we be more pragmatic in our approach?. Sports Medicine, 43(8), 655-663.

Cheung, K., Hume, P., \& Maxwell, L. (2003). Delayed onset muscle soreness: Treatment strategies and performance factors. Sports Medicine, 33(2), 145-164.

Cohen, J. (1988). Statistical power analysis for the behavioral sciences ( $2^{\text {nd }}$ ed.). Hillsdale, New Jersey: Erlbaum.

Fowler, P., Duffield, R., \& Vaile, J. (2014). Effects of domestic air travel on technical and tactical performance and recovery in soccer. International Journal of Sports Physiology and Performance, 9(3), 378-386.

Fowler, P., Duffield, R., \& Vaile, J. (2015a). Effects of simulated domestic and international air travel on sleep, performance, and recovery for team sports. Scandinavian Journal of Medicine and Science in Sports, 25(3), 441-451.

Fowler, P., Duffield, R., Waterson, A., \& Vaile, J. (2015b). Effects of regular away travel on training loads, recovery, and injury rates in professional Australian soccer players. International Journal of Sports Physiology and Performance, 10(5), 546-552.

Goumas, C. (2013). Home advantage and crowd size in soccer: A worldwide study. Journal of Sport Behavior, $36(4), 387$.

Hooper, S.L. \& Mackinnon, L.T. (1995). Monitoring overtraining in athletes. Sports Medicine, 20(5), 321-327.

Hopkins, W.G., Marshall, S.W., Batterham, A.M., \& Hanin, J. (2009). Progressive statistics for studies in sports medicine and exercise science. Medicine and Science in Sports and Exercise, 41(1), 3-13.

Johnston, R.D., Gabbett, T.J., Jenkins, D.G., \& Hulin, B.T. (2015). Influence of physical qualities on post-match fatigue in rugby league players. Journal of Science and Medicine in Sport, 18(2), 209-213.

McGuckin, T.A., Sinclair, W.H., Sealey, R.M., \& Bowman, P. (2014). The effects of air travel on performance measures of elite Australian rugby league players. European Journal of Sport Science, 14(1), 116-122. 
Mendez-Villanueva, A., \& Buchheit, M. (2011). Physical capacity-match physical performance relationships in soccer: Simply, more complex. European Journal of Applied Physiology, 111(9), 2387-2389.

Nédélec, M., McCall, A., Carling, C., Legall, F., Berthoin, S., \& Dupont, G. (2012). Recovery in soccer. Sports Medicine, 42(12), 997-1015.

Pollard, R. (2008). Home advantage in football: A current review of an unsolved puzzle. The Open Sports Sciences Journal, 1(1), 12-14.

Saw, A.E., Main, L.C., \& Gastin, P.B. (2016). Monitoring the athlete training response: Subjective self-reported measures trump commonly used objective measures: A systematic review. British Journal of Sports Medicine, 50(5), 281-291.

Waterhouse, J., Reilly, T., \& Edwards, B. (2004). The stress of travel. Journal of Sports Sciences, 22(10), 946-966.

Winter, E.M., \& Maughan, R.J. (2009). Requirements for ethics approvals. Journal of Sports Sciences, $27(10), 985$.

Submitted: July 14, 2016

Accepted: October 14, 2016

Correspondence to:

Alireza Rabbani

Department of Exercise Physiology

Faculty of Physical Education and Sport Sciences

University of Isfahan, Isfahan, Iran

E-mail: alireza.rabbani@gmail.com

\section{Acknowledgments}

The authors thank Saed Jahangiri for his help during data collection. 